\title{
Determinação da matéria seca e teores de macronutrientes em folhas de frutíferas usando diferentes métodos de secagem
}

\author{
Determination of dry matter and macronutrient content in leaves of fruit trees using different \\ drying methods
}

\author{
Nericlenes Chaves Marcante ${ }^{\mathrm{I} *}$ Renato de Mello Prado ${ }^{\mathrm{II}}$ Marcos Antonio Camacho ${ }^{\mathrm{III}}$ \\ Jean Sérgio Rosset ${ }^{\mathrm{I}}$ Martios Ecco $^{\mathrm{I}}$ Paulo Alberto Legori Savan ${ }^{\mathrm{IV}}$
}

\section{- NOTA -}

\section{RESUMO}

O objetivo desse estudo foi avaliar diferentes métodos de secagem de folhas para três diferentes frutiferas (maracujá, pêssego e abacate), com relação à determinação da matéria seca e os teores foliares de macronutrientes. Foram coletadas amostras de folhas recém expandida de três culturas, do pomar da fazenda de ensino e pesquisa da FCAV-UNESP, câmpus de Jaboticabal, no mês de janeiro de 2010, coletandose para cada cultura 12 amostras com 25 folhas cada. Os tratamentos constituíram-se por dois métodos de secagem, estufa de circulação de ar forçada regulada a uma temperatura de $70^{\circ} \mathrm{C}$ e o forno microondas (FMO). Avaliou-se a massa da matéria seca e os teores foliares de macronutrientes. Os resultados sugerem que os dois métodos de secagem testados se assemelham na determinação de matéria seca e nos teores foliares de macronutrientes para as culturas análisadas, exceto os teores de cálcio na cultura do pêssego.

Palavras-chave: Passiflora edulis sims, Prunus pérsica, Persea lauraceae, nutrientes, forno microondas.

\section{ABSTRACT}

The objective of this study was to evaluate different methods of drying of leaves for three different fruit (passion fruit, peach and avocado), with respect to the determination of dry matter and foliar nutrients. Samples were collected from recently expanded leaves of three crops orchard Farm education and research FCAV-UNESP, Jaboticabal campus, in January 2010, by collecting 12 samples for each culture with 25 leaves. The treatments consisted of two drying methods, greenhouse circulation of air regulated to a temperature of $70^{\circ} \mathrm{C}$ and $F M O$.
We evaluated the mass of dry matter and foliar nutrients. The results suggest that the two drying methods tested did not interfere in the determination of dry matter and foliar nutrients to crops analyzed, except the calcium levels in peach.

Key words: Passiflora edulis sims, Prunus pérsica, Persea lauraceae, nutrients, microwave oven.

A análise química foliar é a principal ferramenta para a avaliação e manejo do estado nutricional das plantas, uma vez que a folha é o órgão que melhor reflete o estado nutricional na maioria das culturas (MALAVOLTA, 2006), isto é, respondem mais as variações no suprimento de nutrientes, por se tratar do centro das atividades fisiológicas dentro das plantas. Logo, entretanto, torna-se de extrema importância a exatidão dos teores presentes nas folhas, não podendo estes sofrerem alterações (perdas) durante o preparo da amostra.

A secagem de material vegetal é definida como uma operação adotada para eliminar a água da superfície e do interior de um material, e tem como objetivo cessar as alterações químicas dos tecidos vegetais e evitar possíveis degradações durante o seu armazenamento, mantendo suas características físicas e químicas por mais tempo (PADILHA et al., 2009).

'Programa de Pós-graduação em Agronomia, Universidade Estadual do Mato Grosso do Sul (UEMS), 79200-000, Aquidauana, MS, Brasil. E-mail: marcantebr@hotmail.com.*Autor para correspondência.

"Departamento de Solos e Adubos, Faculdade de Ciências Agrárias e Veterinárias (FCAV), Universidade Estadual Paulista "Júlio de Mesquita Filho" (UNESP), Jaboticabal, SP, Brasil

"'Laboratório de Nutrição de Plantas, UEMS, Campus de Aquidauana, Aquidauana, MS, Brasil.

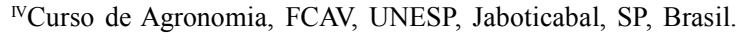


A secagem por forno microondas (FMO) é definida como processo que gera calor no interior do material vegetal, o que, conseqüentemente, acarreta temperaturas mais elevadas do interior até a superfície do material (BARBOZA et al., 2001), ocasionando uma maior rapidez com relação ao tempo de secagem e diminuindo a contaminação por bactérias e fungos, resultando em melhor aparência e qualidade do produto. Trabalhos como de FIGUEIREDO et al. (2004) e LACERDA et al. (2009) relatam que o FMO é uma alternativa mais rápida para a obtenção de matéria seca em forrageiras, uma vez que, há uma eficiência semelhante ao método de secagem em estufa com circulação de ar forçada. Observa-se que as pesquisas que avaliaram métodos de secagem são restritas, comparando apenas o teor de matéria seca no tecido vegetal, entretanto, informações sobre esses métodos de secagem relacionados aos teores dos nutrientes são incipientes na literatura. Deste modo, objetivou-se avaliar a matéria seca e os teores foliares de macronutrientes em três espécies frutíferas, usando diferentes métodos de secagem.

O experimento foi conduzido em condições de laboratório, no período de janeiro a março de 2010, utilizando amostras de tecido vegetal das culturas de maracujá (Passiflora edulis), pêssego (Prunus pérsica) e abacate (Persea lauraceae), secas por dois métodos, sendo o primeiro em estufa de circulação forçada de ar e o segundo em forno microondas (FMO).

As amostragens das três culturas foram feitas no pomar da fazenda de ensino e pesquisa da FCAV-UNESP, câmpus de Jaboticabal, com coordenadas geográficas $21^{\circ} 15^{\prime} 22^{\prime \prime}$ Sul, $48^{\circ} 18^{\prime} 58^{\prime \prime}$ Oeste e altitude de $575 \mathrm{~m}$, com clima mesotérmico de inverno seco (Cwa - Classificação de Köeppen), solo classificado como Latossolo Vermelho-Escuro eutrófico A moderado, textura muito argilosa e relevo suave ondulado, no mês de janeiro de 2010 ,

A coleta foi realizada, utilizando a folha com botão floral na axila, prestes a se abrir, na época do florescimento para a cultura do maracujá, folhas recémmaduras e totalmente expandidas da porção mediana dos ramos, na estação do verão, para o pêssego e folhas entre 5 a 7 meses da altura média das copas, na estação do verão, para o abacate, conforme recomendações de QUAGGIO et al. (1997). As coletas foram feitas em ziguezague, evitando plantas com ataques de pragas e moléstias, obtendo 12 amostras com cerca de 300 folhas para cada cultura, cuidadosamente armazenadas em sacos de papel previamente identificados. O material foi descontaminado pela lavagem, tendo à seguinte sequência: água corrente destilada; solução detergente $(0,1 \%)$; solução de ácido clorídrico $(0,3 \%)$; água deionizada (PRADO, 2008). Em seguida, as amostras foram picadas com auxilio de uma tesoura em partículas com cerca de $20 \mathrm{~mm}$ e levadas ao laboratório para determinação da matéria seca.

Os tratamentos constituíram-se por dois métodos de secagem, pela estufa de circulação de ar forçada regulada a uma temperatura de $70^{\circ} \mathrm{C}$ e o FMO, conforme LACERDA et al. (2009), onde indicam submeter cada amostra a secagem a 3 ciclos de 5 minutos, 1 ciclo de 3 minutos, 1 ciclo de 2 minutos e 1 ciclo de 1 minuto (até atingir massa constante). Em cada intervalo ou ciclo regular, o material vegetal seco em FMO foi desprendido do recipiente com uma espátula, a fim de evitar a fixação na sua superfície e também com intuito de se evitar possibilidade de combustão. No interior do FMO, foi colocado um béquer com $150 \mathrm{ml}$ de água a fim de umedecer o ambiente e evitar a queima das amostras e danos no aparelho.

Após obtenção da matéria seca, as amostras foram moídas em moinho tipo willey e acondicionadas em sacos de papel, para posterior determinação dos teores de macronutrientes, conforme indicações de BATAGLIA et al. (1983). O delineamento experimental utilizado foi um delineamento inteiramente casualizado, utilizando-se dois métodos de secagem em três espécies frutíferas, com 6 repetições, totalizando 36 amostras. Os dados foram submetidos à análise de variância e teste de médias, utilizando-se o software SAS, ao nível de significância de $5 \%$.

Avaliando-se a matéria seca obtida para as folhas de maracujá, pêssego e abacate, observa-se que não ocorreu diferença entre os métodos de secagem testados (Tabela 1). Esses valores semelhantes para o maracujá, pêssego e abacate na determinação da matéria seca pelos dois métodos utilizados, foram igualmente observados por alguns autores, como LACERDA et al. (2009), que relatam a não verificação de diferença entre os métodos de estufa de circulação de ar forçada e FMO para obtenção de matéria seca em forrageiras, igualmente ao observado por FIGUEIREDO et al. (2004) onde os autores mostram que o FMO é uma alternativa viável na determinação rápida e precisa dos teores de matéria seca para o capim elefante em três diferentes estádios de maturidade.

Os resultados referentes aos teores de macronutrientes presente nas folhas das culturas do maracujá, pêssego e abacate (Tabela 1), mostram diferença significativa entre os dois métodos utilizados, somente para o teor foliar de cálcio na cultura do pêssego. Há uma necessidade de ajustes na metodologia de secagem, como nos índices de calibração de temperatura e tempo de secagem em FMO, no qual, possam refletir de maneira mais adequada o teor do nutriente nas folhas, para melhor determinação do estado nutricional do pessegueiro. 
Tabela 1 - Teores de macronutrientes e matéria seca em folhas de maracujá, pêssego e abacate, considerando dois métodos de secagem.

\begin{tabular}{|c|c|c|c|c|c|c|c|c|}
\hline Espécies & Métodos de secagem & $\mathrm{N}$ & $\mathrm{P}$ & $\mathrm{K}$ & $\mathrm{Ca}$ & $\mathrm{Mg}$ & $\mathrm{S}$ & MS \\
\hline \multirow{5}{*}{ Maracujá } & & \multicolumn{6}{|c|}{ - } & $\mathrm{g}$ \\
\hline & Estufa & 37,60 & 1,93 & 25,43 & 19,93 & 2,03 & 5,47 & 10,21 \\
\hline & Microondas & 37,37 & 1,89 & 25,33 & 20,00 & 2,12 & 5,48 & 10,60 \\
\hline & $\operatorname{Pr}>\mathrm{F}$ & 0,656 & 0,393 & 0,919 & 0,899 & 0,220 & 0,923 & 0,354 \\
\hline & Coef. Var. & 2,349 & 4,229 & 6,550 & 4,477 & 5,315 & 5,361 & 6,605 \\
\hline \multirow{4}{*}{ Pêssego } & Estufa & 27,68 & 1,40 & 19,67 & $17,40 \mathrm{a}$ & 3,95 & 2,88 & 23,83 \\
\hline & Microondas & 27,83 & 1,47 & 19,73 & $14,73 b$ & 3,95 & 2,93 & 26,34 \\
\hline & $\operatorname{Pr}>F$ & 0,724 & 0,259 & 0,897 & 0,016 & 1,000 & 0,793 & 0,086 \\
\hline & Coef. Var. & 2,583 & 6,740 & 4,444 & 10,046 & 1,790 & 11,097 & 9,151 \\
\hline \multirow{4}{*}{ Abacate } & Estufa & 17,38 & 0,90 & 7,05 & 12,97 & 4,22 & 3,42 & 32,50 \\
\hline & Microondas & 17,15 & 0,87 & 7,02 & 13,28 & 4,10 & 3,22 & 30,86 \\
\hline & $\operatorname{Pr}>F$ & 0,309 & 0,447 & 0,836 & 0,252 & 0,513 & 0,128 & 0,159 \\
\hline & Coef. Var. & 2,184 & 8,267 & 3,876 & 3,442 & 7,167 & 6,300 & 5,888 \\
\hline
\end{tabular}

Médias seguidas de letras iguais não diferem entre si, na coluna para o tipo de secagem, pelo teste de médias Tukey, em um nível de significância de $5 \%$ de probabilidade.

A ausência de diferença estatística entre as médias dos teores na maioria dos nutrientes, para os dois métodos de secagem, pode estar ligada ao fato de que, as folhas foram picadas em partículas menores antes de serem secas pelo método de estufa com circulação de ar forçada, igual ao relatado por Pirie (1956) apud MARUR \& SODEK (1995). A secagem em estufa com circulação de ar forçada é considerada por alguns autores, um método que ocasiona mudança bioquímica do material vegetal (PASTORINI et al., 2002). No presente estudo, no entanto, diferenças entre os teores de macronutrientes nas três frutíferas avaliadas pelos dois métodos de secagem não foram observadas (Tabela 1).

Os teores de macronutrientes $\left(\mathrm{g} \mathrm{kg}^{-1}\right)$ obtidos para a cultura do maracujá estão dentro da faixa adequada segundo QUAGGIO et al. (1997) e MARTINEZ et al. (1999), boletins técnicos para os estados de São Paulo e Minas Gerais, respectivamente, exceto o magnésio, sendo para estufa com circulação de ar forçada, $\mathrm{N}=36,4-38,9 ; \mathrm{P}=1,8-2,0 ; \mathrm{K}=24-28,2$; $\mathrm{Ca}=18,4-21,4 ; \mathrm{Mg}=1,9-2,2$ e $\mathrm{S}=5,0-5,8$, e para FMO, $\mathrm{N}=36,4-38,5 ; \mathrm{P}=1,8-2,0 ; \mathrm{K}=23,7-28,1 ; \mathrm{Ca}=19,4-21$; $\mathrm{Mg}=2,0-2,3$ e $\mathrm{S}=5,1-5,8$. Confirmando assim, que os dois métodos foram eficientes com relação à obtenção de matéria seca para posterior análise química das folhas do maracujazeiro. As faixas obtidas para os dois métodos foram semelhantes também ao encontrado por HAAG et al. (1973), que foi de $\mathrm{N}=36-46 ; \mathrm{P}=2,1-3,0$; $\mathrm{K}=23,6-32,4 ; \mathrm{Ca}=17,4-27,7 ; \mathrm{Mg}=2,1$ e $\mathrm{S}=4,4$.

Para a cultura do pêssego, as faixas obtidas no presente estudo para o método de estufa com circulação de ar forçada, $\mathrm{N}=26,6-28,7 ; \mathrm{P}=1,4-1,7 ; \mathrm{K}=18,7-$ 20,$7 ; \mathrm{Ca}=15,1-19,7 ; \mathrm{Mg}=3,8-4,0$ e $\mathrm{S}=2,3-3,2$, e FMO, $\mathrm{N}=27,3-28,9 ; \mathrm{P}=1,3-1,5 ; \mathrm{K}=18,7-21,0 ; \mathrm{Ca}=14,1-16,3$; $\mathrm{Mg}=3,9-4,0$ e $\mathrm{S}=2,3-3,2$, estão adequadas com as faixas preconizadas por QUAGGIO et al. (1997), em que o rendimento e a qualidade são satisfatórios, com exceção ao $\mathrm{N}$ para os dois métodos. Já quando comparadas as recomendações de MARTINEZ et al. (1999), as faixas obtidas para os dois métodos, apresentam diferenças com relação aos teores de $\mathrm{P}$ e $\mathrm{K}$.

A mesma observação pode ser feita com relação às faixas na cultura do abacate, onde, para o método de estufa com circulação de ar forçada obtevese, $\mathrm{N}=16,8-17,9 ; \mathrm{P}=0,8-1,0 ; \mathrm{K}=6,6-7,4 ; \mathrm{Ca}=12,3-13,3$; $\mathrm{Mg}=3,9-4,8$ e $\mathrm{S}=3,1-3,7$, eFMO, $\mathrm{N}=16,8-17,5 ; \mathrm{P}=0,8-1,0$; $\mathrm{K}=6,6-7,4 ; \mathrm{Ca}=12,8-13,8 ; \mathrm{Mg}=3,8-4,4$ e $\mathrm{S}=3-3,5$, sendo as duas faixas semelhantes a interpretação considerada adequada por QUAGGIO et al. (1997), sem exceção para qualquer nutriente, com isso, fica claro a possibilidade de utilização dos dois métodos de secagem foliar, para posteriores análises químicas na cultura do abacateiro.

Segundo LAZA et al. (1994), a utilização do FMO para estimar a matéria seca foliar de arroz não influenciou o teor de nitrogênio nesta cultura, assim como no presente estudo, não houve variação do teor de $\mathrm{N}$ para as três frutíferas, comparando os dois métodos de secagem. Os resultados sugerem que os dois métodos de secagem testados não interferem na determinação de matéria seca e nos teores foliares de macronutrientes para as culturas do maracujá, pêssego e abacate, exceto os teores de cálcio na cultura do pêssego. 


\section{REFERÊNCIAS}

BARBOZA, A.C.R.N. et al. Aquecimento em forno de microondas/desenvolvimento de alguns conceitos fundamentais. Química Nova, v.24, n.6, p.901-904, 2001. Disponível em: $<$ http://quimicanova.sbq.org.br/qn/qnol/2001/vol24n6/29.pdf $>$. Acesso em: 25 abril. 2010. doi: 10.1590/S010040422001000600030 .

BATAGLiA, O.C. et al. Métodos de análise química de plantas. Campinas: Instituto Agronômico. 1983. 48p. (Boletim Técnico78).

FIGUEIREDO, M.P. de. et al. Determinação do teor de matéria seca do capim elefante (Pennisetum purpureum Schum), em três estádios de maturidade fisiológica, pelo forno de microondas. Magistra, v.16, n.12, p.113-119, 2004. Disponível em: <http:/ /www.magistra.ufrb.edu.br/publica/magist $16 /$ mag16_2_04_art\%208.pdf>. Acesso em: 20 abril. 2010.

HAAG, H.P. et al. Absorção de nutrientes por duas variedades de maracujá. Anais da ESALQ, n.30, p.267-279, 1973.

LACERDA, M.J.R. et al. Determinação da matéria seca de forrageiras pelos métodos de microondas e convencional. Bioscience Journal, v.25, n.3, p.185-190, 2009. Disponível em: < http://www.seer.ufu.br/index.php/biosciencejournal/article/ viewFile/6901/4569>. Acesso em: 15 abril. 2010.

LAZA, M.R.C. et al. Microwave - oven drying of rice leaves for rapid determination of dry weight and nitrogen concentration. Journal of Plant Nutrition. v.17, n.1, p.209217, 1994.
MALAVOLTA, E. Manual de nutrição mineral de plantas. Piracicaba: CERES, 2006. 631p.

MARTINEZ, H.E.P. et al. Diagnose foliar. In: RIBEIRO, A.C. et al. (Ed.). Recomendação para uso de corretivos e fertilizantes em Minas Gerais: 5 Aproximação. Viçosa: Comissão de Fertilidade do Solo do Estado de Minas Gerais, 1999. p.143-168.

MARUR, C.J.; SODEK, L. Microwave drying of plant material for biochemical analysis. Revista Brasileira de Fisiologia Vegetal. v.7, n.1, p.111-114, 1995. Disponível em: $<$ www.cnpdia.embrapa.br/rbfv/pdfs/download.php?file.pdf $>$. Acesso em: 31 mar. 2010.

PADILHA, V.M. et al. Avaliação do tempo de secagem e da atividade de óxido-redutases de yacon (Smallanthus sonchifolius) sob tratamento químico. Ciência Rural, v.39, n.7, p.2178-2184, 2009. Disponível em: <http://www.scielo.br/ $\mathrm{pdf} / \mathrm{cr} / \mathrm{v} 39 \mathrm{n} 7 / \mathrm{a} 277 \mathrm{cr} 1240 . \mathrm{pdf}>$. Acesso em: 15 abril. 2010. doi: 10.1590/S0103-84782009005000142.

PASTORINI, L.H. et al. Secagem de material vegetal em forno de microondas para determinação de matéria seca e análises químicas. Ciência e Agrotecnologica, v.26, n.6, p.12521258, 2002. Disponível em: <www.editora.ufla.br/revista/26_6/ Vol26_06.htm>. Acesso em: 30 mar. 2010.

PRADO, R.M. Nutrição de plantas. São Paulo: Unesp, 2008. 407p.

QUAGGiO, J.A. et al. Frutíferas. In: RAIJ, B. van. Recomendações de adubação e calagem para o Estado de São Paulo. et al. (Eds). 2.ed. Campinas: IAC, 1997. p.121125. (Boletim Técnico, 100). 